\title{
A Comparative Study on Efficiency Assessment between Public and Private Universities: Evidence from Tanzania
}

\author{
Yustin Ignas Bangi \\ Assistant Lecturer \\ Department of Management Sciences \\ Institute of Finance Management, Shaaban Robert Street \\ P.O. Box 3918, Dar es Salaam, Tanzania \\ E-mail: ybangi67@gmail.com
}

\section{ABSTRACT}

Our study builds on a two- stage Data Envelopment Analysis to examine and compare the efficiency of public and private universities in Tanzania in 2008-2012. First, we use data envelopment analysis to measure the technical and scale efficiency of universities. Secondly, we examine factors that influence efficiency through Tobit regression model for both public and private Universities. The findings from the model affirm that the efficiency of the two University categories varies significantly. However, public University average efficiency is observed to be higher than that of private Universities. Whereas public Universities are inefficient in research and publications, private universities efficiency is determined by enrolment, academics staff and consultancy services. Given the contemporary significance of University education to social and individual development, we plead to the government University agency (TCU) to review the entire quality assurance process to improve Universities efficiency.

Key words: Universities; Efficiency; Public Universities; Private Universities; DEA mode.

\section{Council for Innovative Research}

Peer Review Research Publishing System

Journal: International Journal of Management \& Information Technology

Vol. 10 No. 1

editorsijmit@gmail.com

www.ijmit.com/ojs 


\subsection{INTRODUCTION}

University education has now become a cornerstone and precedence of all countries regardless of their development levels. It is from Universities where skilled man power derives and supply labour to different organizations both public and private sectors. As pervasive actors, Universities provide competitive advantage to countries in the international arena, as well as high income to individuals. In this regard, University efficiency measurement is indispensable, so that they remain competitive by meeting stakeholders' demand. Through efficiency measurement. Organizations get to know if they are spending the resources invested inexpensively (El-Demerdash et al, 2013).

In Tanzania, Universities refers to a post secondary education leading to the award of Advanced diploma, Bachelor degree, Masters, Postgraduate Diploma and PhD degrees. Public Universities on the one hand are established, operated and maintained by the government. On the other hand, private Universities are established and operated by private organizations or individuals. However, both public and private Universities are controlled by the government (URT, 1999). Thus, public and private Universities operate in partnership bases.

Prior to financial crisis in 1980s, Tanzania had monopoly on policy, planning and provision of higher education. However, University education was not given priority as it was seen to provide no or little social returns compared to other preceding levels of education. Therefore, a focus was given to primary, secondary and vocational education. These were the ones considered to provide more social returns (Abel, 2010). Worse enough, higher education was not even recognised by gigantic national plans like "The National Stratage for Growth and Reduction of Poverty (NSGRP 2005), popularly known as MKUKUTA in Kiswahili acronym.

Like elsewhere in developing countries, Africa in particular, it took some years to realise the contribution of higher education in development. However, the benefits of University outputs are indisputable. For instance, it is from Universities where potential man power emanates. These include; teachers at all levels of education, decision makers in the government and related organizations, to name a few, are prepared in Universities. Above all, Universities disseminate knowledge, provide consultancy services and conduct research for development. Consequently, the government has now strengthened partnership with private Universities in education, which were legally permitted to operate in 1995. To emphasize more, in 2009, the government put in place a public private partnership (PPP) policy. It has been realised that PPP is a viable means of achieving both socio-economic good and social services by the government (URT, 2009).

These sister policies, have accelerated the increase of Universities in Tanzania, from one University in 1970 to more than 40 Universities in 2014 (TCU, 2014). Eventually, the increase of Universities has also raised the enrolment. Between 2010 and 2011 , for instance, there was an increase of enrolment by $49 \%$. Despite this tremendous change, the efficiency and quality of Universities remain sceptical. Nevertheless, evidence from stakeholders' complaints about performance of graduates is vibrant. The incapability of University graduates has been reported, that they are unable to demonstrate the desired skills at the work place. In this scenario, organizations have undermined the role of Universities, and they are reluctant to employ University graduates (Bastos, 2011). To emphasize more, Msolla (2000) pointed out the prevailing complaint from the society about poor education quality. It was suggested to redress the situation through linking expansion of higher education with quality assurance of the education being offered for.

In line with this allegation, Makulilo (2013) also avows that proliferation of private Universities in Tanzania has led to the decline of education quality. However, this contradicts to Liu (1992) who states, ownership of an enterprise is empirically not a significant factor of performance. It is also unreasonably to relay on only one empirical study to reach conclusion, rather the same can be added to a body of evidence for further evaluation. Therefore, still more evidences are required to justify if private Universities are the major cause of education decline. Furthermore, Materu (2007) support Makulilo's assertion that entrance of private sectors and international providers of University education has decelerated both quality and efficiency of education. Additionally, financial constraints and human resource incapability are identified as the major causes of this tragedy.

On the other hand, Ferguson and Ferguson (1994), contradicts the hypothesis that public institutions are inherently poor performers than private enterprises. The reason provided to defend this stance is deficit of information driving to such conclusion. Moreover, most public enterprises do not have a specific benchmark for which their performances can be measured. Furthermore, their social activities are explicitly than that of private sectors. Thus, it is difficult to compare these two enterprises due to their varied nature of performance environment.

In a similar way, Thomas and Xiaoying (2009), highlights the impact of ownership on higher education institutions on performance and efficiency due to different institutional setting, priorities, perceptions, experience and others. Likewise, public and private Universities differ in various aspects such as resource capability, orientations in terms of education delivery if it is for service or business, management styles and the like (Alam, 2009). As result of these variations, efficiency variability could also be possible. This can only be realised through efficiency measurement of both.

Studies elsewhere have also revealed incongruity concerning higher education efficiency and quality. In Greece, Panagiotakopoulos (2012), while studying employability skills found that higher education institutions have failed to integrate desired skills in their curriculum, as result graduates are not esteemed in the world of work. Implicitly, Universities and their regulators do not play their role accordingly, and the future of University graduates is not determined in case the situation is not redressed. Even though, the study is not bias on whether public or private Universities are the source of the problem.

Notwithstanding scepticism about Universities, the argument that Universities should prepare employable graduates has no objection. As Fallows and Steven (2000), Hall et al 92009) and Harvey and Knight (1996) state, graduates 
employability skill competence, should be a paramount criteria which also need to be incorporated within a University curriculum.

Based on ongoing conflicting debate on whether public or private Universities are the source of the prevailing University education problem, this study examines the efficiency of both public and private University, and compares their efficiency. This paper is organized as following: In the second section, related literature review is provided, followed by methodological part in section three. Findings and discussions are provided in section four. Finally, section five presents conclusion and recommendations.

\subsection{LITERATURE REVIEW}

In economics term, efficiency is the ratio between the total output and total input. A firm is said to be efficient if it uses certain amount of input to produce more outputs, or spending less input resources to produce the same amount of outputs under given technology, as compared to other firms (Vincová, 2005 ). Therefore, University efficiency implies ability to use minimum education resources to produce desired outputs/outcomes such as research, consultancy services, and graduates, to name a few.

Measuring education efficiency has been very difficulty due to multiple inputs and outputs involved. In education the variable inputs are not directly related to outputs obtained. As result, efficiency assessment uses a proximal relationship between inputs and outputs. However, a non-parametric linear model, data envelopment analysis (DEA) has been in use for more than three decades in measuring the efficiency of various organizations, including education institutions. This is a linear programming paradigm which makes no prior assumption about variables (Aristovnik, 2013).

Toth (2009) implemented DEA in assessing the efficiency of higher education systems in European countries based on gross domestic product (GDP) per capital and parents' education through DEA. The findings indicate that there is a positive relationship between GDP per capital and education higher education achievement. Another study by Ying Chu $\mathrm{Ng}$ (2000); Worthington (2001); Warning (2004); employed similar model in assessing the efficiency of Universities. Results from these studies reveal that there is variability of efficient among Universities. Furthermore, it is affirmed that an institution being efficiency in one aspect however, does not guarantee efficiency on another. Obviously, the efficiency or inefficiency will only base on involved inputs and output variables of a particular unit. Thus, an institution being efficient or inefficient is not a permanent behaviour; it is determined by particular environment in which an institution operates.

Moreover, Collier (2012) assessed the effect of institutional arrangement on student achievement in schools, using a two stage regression model and DEA model. The findings obtained suggest that there is a positive influence of institutional setting to student achievement. However, a slight relationship between educations' input like salaries and teachers on school efficient was observed. The use of DEA model is also emphasized by Abdulkareem and Oyeiran (2011) that Universities need to provide services to their clients while focusing on the market needs. They suggest that this can only be realised through DEA approach by analysing their efficiency.

In contrast, Ghana has reported a brain drain crisis focusing on Medical professional graduates (Dovlo and Nyonator, 2005). Findings from the study conducted in Sub-Saharan countries to detect the deficiency of medical Doctors reveal that most of professional Doctors seek jobs to abroad to earn more returns. Arguably, there variations of efficiency among University schools and departments in terms of graduate qualities. So, similar case should be expected when comparing public and private Universities efficiency.

Despite the overwhelming demand of graduates in the world of work, Universities are blamed for not preparing graduates who possess desired skills (Sutherland, 2008). Surprisingly, studies indicate policy successes while leaving graduates unemployed as they enter into the market without qualifications. To support the same, Ordonez (2012) states that Universities should train graduates who can be easily sucked by the global market. This will meet their dreams of working abroad and earning higher income. These arguments imply the challenges Universities face in terms of efficiency, as they cannot meet the social expectations. This has become a hurdle to most graduates who graduate without acquiring market desired skills.

In the same way, the current competition in higher education calls for constant measurement activities of these institutions to improve their efficiency (Nkirila, 2009). It is further stated that both public and private higher education institution needs to comply with government mandates, if they are to improve their efficiency. Therefore, Universities need to strike the balance between their increase in number and efficiency, while focusing on the three core objectives namely; knowledge transmission, knowledge creation and knowledge sharing to the society.

Many studies done in Tanzania focuses on other higher education such as quality, access, equity and financing of higher education, to name a few. The aspect of University efficiency is scantly discussed; for instance Kapinga and Dunrong (2010), their study determined reasons for higher education privatization and revealed that government fiscal incapacitation and delayed meeting social demand triggered privatization of higher education. Ishengoma (2008) assessed the trend of cost sharing higher education and realised that there were more challenges than solutions to arrest. Uneven distribution of funds and low capacity of the government to provide sufficient loans were some of the identified hurdles. A study by Makulilo (2012) on the proliferation of private universities in Tanzania focused on private Universities public Universities affirmed that private Universities were the major cause of low quality of University graduates. However, an interesting study by Kipesha (2013), done on public Universities efficiency, provide an impetus to the current, as it did not assess the efficiency of both University categories (public and private). None of the studies has compared the efficiency of public and private Universities for concrete inference. Therefore, we conduct this study to examine and compare the efficiency of both public and private Universities in Tanzania. 


\subsection{METHODOLOGY}

Data environment analysis (DEA) is powerful statistical tool which is broadly used to measure efficiency and performance of different decision making units (DMU). Usually, the investigated DMUs are characterized by multiple inputs and multiple outputs. Some of these variables are stochastic, making it difficult to execute other approaches than DEA model. Thus, with DEA model, DMUs transform multiple inputs into multiple outputs. The objective of DEA is to assess the efficiency of each comparable DMUs in relation to its peers. Additionally, DEA determines the sources of inefficiency and suggest solution for remedy.

The current study therefore, adopts an input oriented two stage DEA model. In stage one a technical efficiency and scale efficiency is obtained by performing two DEAs. The second stage uses Tobit regression to determine efficiency influencers. The first DEA, assumes that DMUs operates at constant return to scale (CRS), suggested by Charnes, Cooper and Rhodes (1978) CCR model. The second analysis is under assumption that the DMUs are operating at variable return to scale (VRS) as introduced by Barker et al (1984) namely; BCC model, modified from CCR model. Nevertheless, in real life optimal behaviour is unacceptable due to various factors such as, financial constraints, market competition, technological change and others (Cesaro, 2009). Thus, we prefer both CRS and VRS formulation due to the fact that public and private Universities relatively differ in terms of size, resources and orientations. This will facilitate to obtain the mean technical efficiency of both public and private Universities, and compare their means. Moreover, the decomposition of technical efficiency (TE) into scale efficiency (SE) is calculated given by:

$$
S E=\frac{\mathrm{TE}_{\mathrm{CRS}}}{\mathrm{TE}_{\mathrm{VRS}}}
$$

All CRS, VRS and SE can vary from zero and one. A score of one indicated by $100 \%$ implies a DMU is full efficient, whereas any score below that indicates inefficient of a DMUs.

\subsection{CCR Model (CRS)}

The original model was proposed by Charnes et al (1978). CCR introduced the following fractional programming problem to obtain values for input weights and output weights. Basic CCR formulation is;

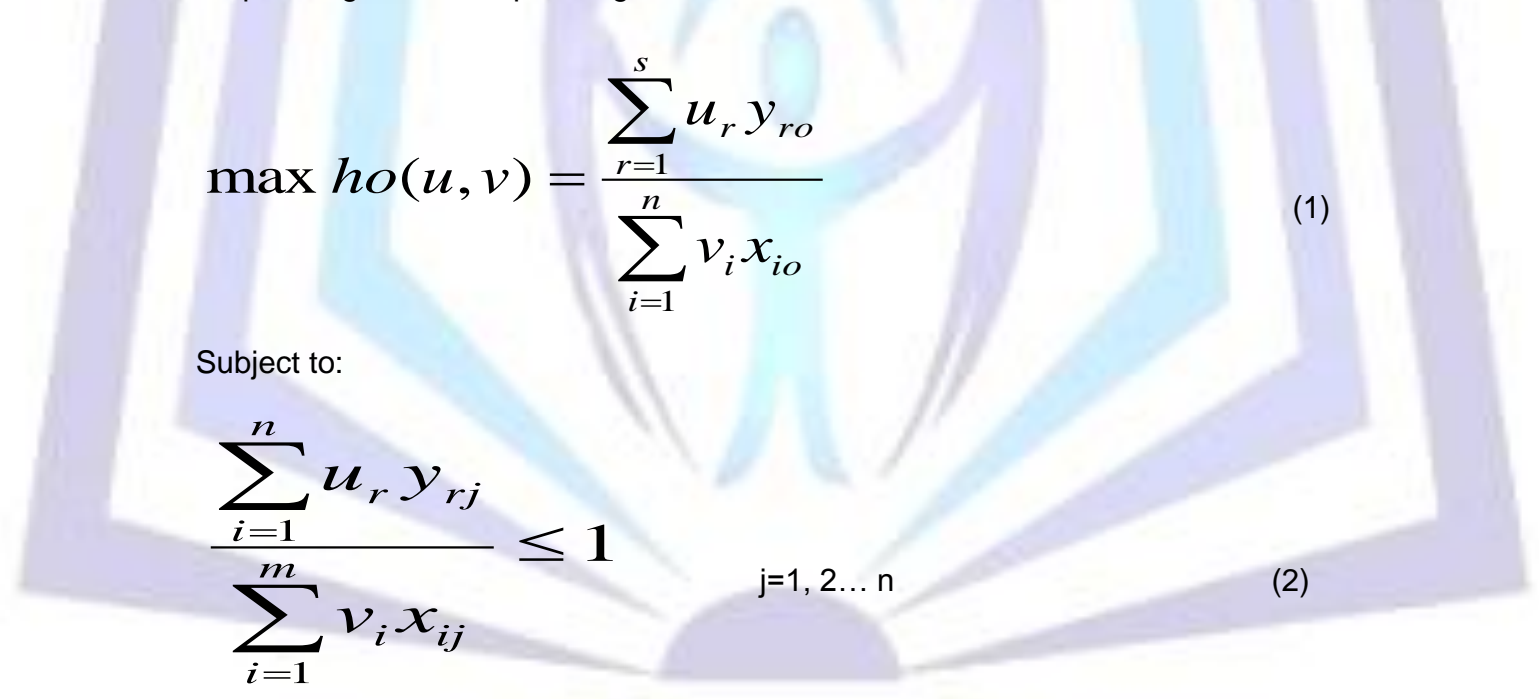

$$
\begin{array}{ll}
u_{r} \geq 0 & \mathrm{r}=1,2 \ldots \mathrm{s} \\
v_{i} \geq 0 & \mathrm{i}=1,2 \ldots \mathrm{m}
\end{array}
$$

Where $x_{i j}$ is the observed amount of input ith of the jth DMU $\left(x_{i j}>0, j=1,2 \ldots n ; i=1,2 \ldots m\right)$ and $y_{i j}=$ observed amount of output of the rth type for the jth DMU $\left(y_{i j}>0, r=1,2 \ldots s ; j=1,2 \ldots n\right)$

\subsection{The BCC Model (VRS)}

As aforementioned, the CRS DEA model assumes that the DMUs are operating at an optimal scale. So, the implication of this model is that technical efficiency of DMUs does not vary. However, in real life, it is impractical. To remedy this 
situation, Banker, Charnes and Cooper (1984) have taken it on board, through extended DEA to the case. This model disentangles between pure technical efficiency (PTE) and scale efficiency (SE), identifying if increasing, decreasing or constant returns to scale are present. Therefore, the original CCR model has to change by finding its dual as following:

$$
\min h_{o}(u, v)=\theta
$$

Subject to:

$$
\begin{gathered}
\sum_{j=1}^{n} \lambda_{j} y_{r j} \geq y_{r o} \\
\theta_{o} x_{i o}-\sum_{j=1}^{n} \lambda_{j} x_{i j} \geq 0 \\
\sum_{j-1}^{n} \lambda_{j}=1 \\
\lambda_{j} \geq 0
\end{gathered}
$$

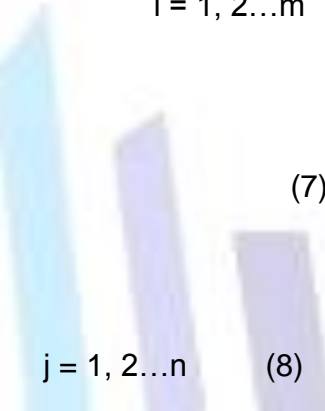

Where $x_{i j}$ is the observed amount of input ith of the jth $\operatorname{DMU}\left(x_{i j}>0, j=1,2 \ldots n, i=1,2 \ldots n\right)$ and $y_{i j}=$ observed amount of output of the rth type for the jth DMU $\left(y_{i j}>0, r=1,2 \ldots 3, j=1,2 \ldots n\right)$

\subsection{Tobit regression Model}

Tobit regresssion model is a statistical non-linear model proposed by James Tobin to describe the relationship between a non-negative dependent variable $Y_{i}$ and an independent variable $X_{i}$. This model is used to examine the factors that influence efficiency for appropriate correction of inefficient DMUs (Foster, 2013). This is the second stage of efficiency analysis we implement a Tobit regression model. Therefore, Tobit regression equation created in this study has efficiency scores of each University as dependent variable and factors that are considered to influence the efficiency scores are independent variables. With Tobit regression results, a variable is considered significant if its $P$-value is $(0.01 \leq P \leq 0.05$ or $t$-value $\geq|1.96|$. We run two regressions to determine the factors influencing efficiency in public Universities as well as factors influencing efficiency in private Universities.

\subsection{Data and variables}

The Data employed in this study are both primary and secondary quantitative derived from multiple sources. Secondary data were derived from Tanzania Commission for Universities (TCU), National Bureau of Statistics (NBS) and Ministry of Education and Vocational Training (MoEVT), whereas primary data were obtained from 16 Universities in Tanzania those which were ready to provide data. The sample includes 8 public and 8 private Universities. However, we intended to use the entire population but unavailability of data is one of the limitations to this study.

We use a panel data for the period of 2008 to 2012 . The selection of this period is based on two factors. First, this is the period when high enrolment was recorded in Tanzania Universities, resulting from massive increase of graduates in secondary schools and non-university colleges. The graduate increase in secondary schools was also accelerated by the secondary education development plan commenced in 2004-2009 (URT, 2004). Secondly, in 2010 MoEVT launched a higher education development plan (HEDP) to curb the increased enrolment in secondary schools, demanding for higher education (URT, 2010). Thus, it is worthwhile to assess the University efficiency to ascertain if the adapted plan is workable. So, we select inputs which are proximal to the selected output as shown in the table below due to complexity of educational variables. 
Table 1 Input and output variables for both public and private Universities

\begin{tabular}{ll}
\hline \multicolumn{1}{c}{ Input Variables } & \multicolumn{1}{c}{ Output Variables } \\
\hline Total enrolment (EN) & Number of Graduates (GR) \\
Number of academic staff (AS) & Number of research publications (RP) \\
Number of non-academic staff (NAS) & Number of consultancy services (CS) \\
\hline
\end{tabular}

\subsection{RESULTS AND ANALYSIS}

This section, provide results from the two DEA modelling, for public Universities and private Universities. From the results, the technical efficiency and scale efficiency scores are examined, and their average means of the two University categories are compared. Furthermore, results from Tobit regression model are presented to ascertain the determinants of technical efficiency in public Universities as well as in private Universities.

\subsection{Technical efficiency DEA results}

After performing a two DEA analysis, we obtain mean technical efficiency under CRS and VRS assumptions. Scale efficiency (SE) is obtained from the ratio of CRS and VRS. Detailed output by institution is shown in Appendices A and B. All score values for CRS, VRS and SE rows, varies from zero to one, where $100 \%$ implies technical efficient or scale efficient. Any efficiency scores less than $100 \%$, indicates technical inefficient or scale inefficient of that DMU.

Table 2 Mean Technical Efficiency DEA results (2008-2012)

\begin{tabular}{lcccc}
\hline YEAR & Return to Scale & Public University & Private University & Difference \\
\hline 2008 & CRS & $96.06 \%$ & $71.44 \%$ & $24.63 \%$ \\
& VRS & $96.06 \%$ & $92.49 \%$ & $3.58 \%$ \\
2009 & SE & $100.00 \%$ & $76.39 \%$ & $23.61 \%$ \\
& CRS & $94.28 \%$ & $83.53 \%$ & $10.75 \%$ \\
2010 & VRS & $97.50 \%$ & $92.38 \%$ & $5.13 \%$ \\
& SE & $96.62 \%$ & $90.97 \%$ & $5.65 \%$ \\
2011 & CRS & $94.33 \%$ & $85.91 \%$ & $8.41 \%$ \\
& VRS & $97.38 \%$ & $94.66 \%$ & $2.71 \%$ \\
& SE & $96.14 \%$ & $90.97 \%$ & $5.17 \%$ \\
& CRS & $93.23 \%$ & $81.63 \%$ & $11.60 \%$ \\
& VRS & $96.74 \%$ & $93.73 \%$ & $3.01 \%$ \\
& SE & $96.31 \%$ & $85.32 \%$ & $10.99 \%$ \\
& CRS & $94.28 \%$ & $90.88 \%$ & $3.40 \%$ \\
& VRS & $96.64 \%$ & $93.25 \%$ & $3.39 \%$ \\
& SE & $97.08 \%$ & $96.48 \%$ & $0.60 \%$ \\
& No. OF DMUS & 8 & 8 & \\
\hline
\end{tabular}

Source: Research Data

From table 2 it is observed that when institutions are modelled under CRS in all the five years of review, public Universities and (private Universities) on average are operating at $(96.06 \%)(71.44 \%), 94.28 \%(83.53 \%), 94.33 \%(85.91 \%)$, $93.23 \%(81.63 \%)$ and 94.28\%(90.88\%) technical efficiency in 2008, 2009, 2010, 2011 and 2013 respectively. Similarly, when institutions were modelled under VRS using five year panel data, public Universities and (private Universities) on average are operating at $96.06 \%(92.49 \%), 97.50 \%(92.38 \%), 97.38 \%(94.66 \%), 96.74 \%(81.63 \%)$ and $96.64 \%(93.25 \%)$ technical efficiency in 2008, 2009, 2010, 2011 and 2012 respectively. Turning to the third row of each examined year, the average scale efficiency indicates that on average, Universities public and (private) are operating at $100.00 \%(76.39 \%)$, $96.62 \%(90.97 \%), 96.14 \%(90.97 \%), 96.31 \%(85.32 \%)$ and $97.08 \%(96.48 \%)$ scale efficient. Generally, results demonstrate that public Universities' mean average scores of technical efficiency and scale efficiency are higher than that of private Universities. Additionally, in 2008 all public Universities are observed to operate under $100 \%$ mean scale efficient. 
On the other hand, private Universities are scale inefficient in all five years of review. It is further noted that the maximum percentage difference of their mean efficiency between public and private Universities is $24.63 \%$ (CRS) and the minimum is $0.60 \%$ (SE). That is to say, the Universities' efficiency varies largely when operated under CRS and there is scant difference on the scale efficiency, and their mean averages are high close to $100 \%$.

\subsubsection{Average number of efficient Universities from 2008-2012}

This is intended to observe the average number of efficient Universities, both public and private in each year of review, and detect if there is any variation between them. Table 3 below indicates the average number of efficiency Universities in the five years of review. Details of the results are in Appendix C, which is also extracted from Appendices A and B, indicating University efficiency scores modelled under CRS, VRS and SE.

Table 3 Average number of efficient Universities from 2008-2012

\begin{tabular}{|c|c|c|c|c|}
\hline EFFICIENCY & $\begin{array}{c}\text { Efficient Public } \\
\text { Universities }\end{array}$ & $\%$ & $\begin{array}{c}\text { Efficient Private } \\
\text { Universities }\end{array}$ & $\%$ \\
\hline CRS & 6 & $75.0 \%$ & 5 & $62.5 \%$ \\
\hline VRS & 6 & $75.0 \%$ & 6 & $75.0 \%$ \\
\hline SE & 4 & $50.0 \%$ & 5 & $62.5 \%$ \\
\hline
\end{tabular}

Based on the results in table 3, it is noted that on average the number of efficient public (Private) Universities are 6(75.0) $5(62.5 \%), 6(75.0 \%) 6(75.0 \%)$ and $4(50.0 \%) 5(62.5 \%)$ when Universities operate under CRS, VRS and SE respectively. Thus, while an average of 6 public Universities are technically efficient under CRS, 5 Universities are also efficient under the same behaviour. However, it is learned that both public and private Universities have an equal average number $(75.0 \%)$ of efficient Universities when operate under VRS. Under such situation, it can be argued that both University categories are affected by similar factors which render them not to become efficient. Under scale efficiency, the average number of efficient public Universities is $4(50.0 \%)$ while that of private Universities is $5(62.5 \%)$. Arguably, most private Universities seem to be more scale efficient compared to public ones. From general observation, it can be argued that there is slightly difference in terms of average number of efficient Universities in the reviewed time.

\subsection{Result from Tobit Regression Model analysis}

\subsubsection{Tobit regression for public Universities}

We use Tobit regression model to examine the public University efficiency determining factors. The analysis is performed at $5 \%$ level of significance for both public and private Universities. In this case technical efficiencies modelled under VRS (Appendices A and B) are employed for both DEAs in public and private Universities.

Regression equation for public Universities is statically represented by;

$\theta P U i=\beta O P U i+\beta 2 E N P U i+\beta 2 A S P U i+\beta 2 N A S P U i+\beta 2 G R P U i+\beta 2 R P P U i+\beta 2 C S P U i+u P U i$

Where,

ӨPUi is the efficiency of public Universities $\mathrm{i}, \beta O P U i$ is the constant term, ENPUi total enrolment in public Universities, NASPUi is non-academic staff public Universities, GRPUi number of graduates public Universities, RPPUi research publication public Universities, CSPUi consultancy services public Universities, $\beta 1$ PUi- $\beta 6 P U i$ are coefficient of variable from 1 to 6 public Universities and uPUi is the error term in public Universities.

Table 4 Tobit Regression Model Results - Public Universities

\begin{tabular}{lrrrrr}
\hline \multicolumn{1}{c}{ Efficiency } & Coefficient. & Std. Err. & t & P>t & \multicolumn{1}{c}{ [95\% Conf. } \\
\hline & & & & & \\
Enrolment & $3.21 \mathrm{E}-06$ & $5.62 \mathrm{E}-06$ & 0.57 & 0.571 & $-8.21 \mathrm{E}-06$ \\
Academic staff & -0.0005522 & 0.0003158 & -1.75 & 0.089 & -0.0011939 \\
Non-academic staff & 0.0002075 & 0.0001548 & 1.34 & 0.189 & -0.0001072 \\
Graduates & 0.0000315 & 0.0000191 & 1.65 & 0.108 & $-7.22 \mathrm{E}-06$
\end{tabular}




$\begin{array}{lrrrrr}\text { Research publication } & -0.0002912^{*} & 0.0001145 & -2.54 & 0.016 & -0.000524 \\ \text { Consultancy services } & 0.0020029 & 0.0011699 & 1.71 & 0.096 & -0.0003745\end{array}$

Source: Own Calculations

* Significant variable

The result in table 4 show that only research publication (RP) is significant at $5 \%$ level of significance and its relationship with efficiency is negative. This signifies that public Universities could reduce their efficiency by any increase of $0.03 \%$ of research and publication. Similarly, inefficient public Universities could increase their efficiency scores to $100 \%$ through reduction of research publications by the same quantity of $0.03 \%$. So far, other variables have indicated no statistical significance to the efficiency of public Universities. The implication to this is that public Universities are operating at high average of efficiency. This is also supported by an average TE and SE in Table 2.

\subsubsection{Tobit regression for private Universities}

Regression equation for private Universities is statically represented by;

$\delta P R U i=\beta 0 P R U i+\beta 2 E N P R U i+\beta 2 A S P R U i+\beta 2 N A S P R U i+\beta 2 G R P R U i+\beta 2 R P P R U i+\beta 2 C S P R U i+u P R U i$

Where,

$\delta P R U i$ is the efficiency of private Universities $i, \beta O P R U i i s$ the constant term, ENPRUi total enrolment in private Universities, NASPRUi is non-academic staff private Universities, GRPRUi number of graduates public Universities, RPPRUi research publication private Universities, CSPUi consultancy services private Universities, $\beta 1 \mathrm{PUi}-\beta 6 \mathrm{PUi}$ are coefficient of variable from 1 to 6 private Universities and uPUi is the error term in private Universities.

Table 5 Tobit Regression Model Results - Private Universities

\begin{tabular}{lcrrrr}
\hline \multicolumn{1}{c}{ Efficiency } & Coefficient. & Std. Err. & \multicolumn{1}{c}{ t } & P>t & [95\% Conf. \\
\hline Enrolment & $-0.0000992^{*}$ & $4.77 \mathrm{E}-05$ & -2.08 & 0.045 & -0.0002 \\
Academic staff & $0.0016181^{*}$ & 0.000685 & 2.36 & 0.024 & 0.000226 \\
Non-Ac. Staff & 0.0004274 & 0.000235 & 1.82 & 0.078 & -0.00005 \\
Graduates & 0.000107 & 0.000157 & 0.68 & 0.499 & -0.00021 \\
Research \& pub & -0.0045482 & 0.00339 & -1.34 & 0.189 & -0.01144 \\
Consultancy services & $0.016335^{*}$ & 0.00726 & 2.25 & 0.031 & 0.001582 \\
\hline Source: Own Calculations & & & & &
\end{tabular}

Table 5 above show that enrolment (EN), academic staff (AS) and consultancy services (CS) are statistical significant to private Universities efficiency. Whereas enrolment shows negative relationship with efficiency indicated by a negative sign coefficient, academic staff and consultancy services are positively related with the University efficiency. In this regard, inefficient private Universities could reduce the number of student enrolment by $0.01 \%$, at the same time increase the number of academic staff by $(0.20 \%)$ and number of consultancy services by $(1.63 \%)$, if they are to become efficient. It is learned from the results that private Universities enrol more students over and above their capacity in other resources like academic staff. Thus, a balance between inputs and outputs could raise the efficiency.

\subsection{DISCUSSIONS AND CONCLUSION}

It is clearly stated earlier that assessing Universities' efficiency is a pervasive role of any government aspiring to attain sustainable development. This paper examines the public and private Universities efficiency, whereby a comparison between the two University categories is also done. The overall findings suggest that the there is statistical variation between mean technical and scale efficiency averages of public and private Universities in Tanzania. However, mean averages of public Universities are observed to be higher than that of private Universities, in all DEA modelling; CRS, VRS and SE. However, high variation is observed in CRS and a very low difference in SE. High variation in CRS results from the fact that CRS is not very practical due to variation factors hindering Universities not to operate under this assumption (Cesaro, 2009). Not only that but also, public Universities differs in terms of resources, experience, government support, management etc. All these, might have contributed to the observed results.

There is also an indication that public Universities have only one efficiency determinant to inefficient Universities, whereas there are three determinants for private Universities. Research publication in public Universities appear to be negatively related to efficiency. The implication to this is that inefficient Universities could reduce this factor by $0.03 \%$ to become efficient. Student enrolment is observed to be higher than the capability of the University to handle. Since tuition fee is the major source of running private Universities, it is clearly learned that raising fund through fees is paramount to private 
Universities. In so doing, causes efficiency to decline. Contrary to that, academic staff and consultancy services are found to be positively significant to University efficiency, hence requiring them to increase these variables.

Both hiring academic staff and conducting consultancy services are investments which consume University funds. Implicitly, private Universities do not capitalize on hiring more academic staff; rather they employ few, so as to incur less cost and maximize profit. To bridge the gap of academic staff they mainly depend on part time lecturers who are also cheaply paid. Likewise, private Universities do not invest much on consultancy, they mainly focus on teaching. This is in line with Hirshleifer (1980), argues, "According to the classical formulation, the aim of the firm as a decision-making agent is to maximize (economic) profit" (p. 265). In this case, there is no doubt that the orientation of private is for profit making while that of public Universities is for service delivery. Therefore, private Universities could increase these variables so as to elevate their efficiency.

Conclusively, we affirm that the existing efficiency variations between public and private Universities, is very significant and has a policy implication. The government through its agency (TCU) need to review its entire process of quality assurance to ensure that efficiency assessment is frequently and thoroughly done. All University stakeholders such as academic staff, entrepreneurs, parents, students, and alumna to name a few, could be involved to provide inputs on how efficiency can be attained and maintained. Nevertheless, this study precluded other exogenous factors which might have contributed to this finding. Consequently, we suggest another study of the same by increasing the sample of Universities and other qualitative variables which could come up with different findings.

\subsection{ACKNOWLEDGEMENT}

This study has been successful due to contributions of many people who assisted me in one-way or another. I wish to express my sincere appreciation to all. The fact that I can not mention each by name makes debt to them even bigger. However, I am first of all very grateful to Dr. A. Sahay for his tolerance and tireless efforts in supervising and reading my paper. I declare that his guidance has been very valuable in successful production of this paper. I wish to extend my sincere gratitude to the management of Public and Private Universities in Tanzania, Ministry of Education and Vocational Training (MoEVT), Tanzania Council for Universities (TCU) and National Bureau of Statistics, for their readiness to provide data for this study. Finally but not least, I extend my sincere thanks to the Institute of Finance Management (IFM) for sponsoring my PhD studies at BIMTECH.

\section{REFERENCES}

[1] Abdulkareem, A.Y and Oyeniran, S. 2011, Managing the performance of nigerian Universities For sustainable development using data envelopment analysis, International Journal of Academic Research in Business and Social Sciences, August 2011, Vol. 1,

[2] Alam, G.M. 2009. Can governance and regulatory control ensure private higher education as business or public goods in Bangladesh

[3] Aristovnik, A. 2013. Relative efficiency of public education in the new EU member states: the case of primary education, international conference, University of Ljubljana

[3] Banker R, D., Charnes, A. and Cooper W. 1984. Some models for estimating technical and scale inefficiencies in data envelopment analysis. Management Science 30: 1078-1092.

[4] Bastos, C. A and Rebois, R. R. 2011. Review and evaluation of the performance of Tanzania's HEls in Science, technology and Innovation

[5] Buckner, E. 2011. The Role of higher education in the Arab state and society: historical legacies and recent reform patterns, Comparative \& international higher education 3 (2011), Stanford University, USA

[6] Charnes, A, Cooper, W.W and Rhodes, E 1978. Measuring efficiency of decision making unitsll, European Journal of Operation Research, vol. 2, no. 6, and pp. 429-44

[7] Cesaro, L. (2009), Methodology for analysing competitiveness, efficiency and economy of scale, use and applications of DEA, FACEPA Deliverable No. D5.1.3 - April 2009, INEA - Italy

[8] Collier, T (2012), The Impact of Institutional arrangements on educational efficiency, The Open Economics Journal, $2012,5,1-14$

[9] Dovlo, D. and Nyonator, F. (2005), Migration by graduates of the University of Ghana medical school: a preliminaryzrapid appraisal, Ministry of Health, Accra, Ghana.

[10] Erasmus, Kipesha, F. and Msigwa, R. 2013. "Efficiency of higher learning institutions: evidences from public Universities in Tanzania", Journal of education and practice ISSN 2222-1735 (Paper) ISSN 2222-288X (Online) Vol.4, No.7, 2013 www.iiste.org

[11] El-Demerdash, B. E. El-Khodary, I. A. and Tharwat, A. A. 2013. Developing a stochastic input oriented data envelopment analysis (SIODEA) Model, (IJACSA) International Journal of Advanced Computer Science and Applications, Vol. 4, No. 4, 2013

[12] Fallows, S. and Steven, C. 2000. Integrating key skills in higher education: employability, transferable skills and learning for life, Kogan Page, London 
[13] Ferguson, P. R. and Ferguson, G. J.1994. Industrial economics: issues and perspectives. Basingstol and London: Macmillan.

[14] Foster, G. and Kalenkoski, C. M. 2013. Tobit or OLS? An empirical evaluation under different diary Window Lengths, Applied Economics, 2013, 45, 2994-3010

[15] Hall, M., Higson, H. and Bullivant, N. 2009. The role of the undergraduate work placement in developing employment competences: Results from a 5 year study of employers, Aston business school, Birmingham, available at: www.decowe.com/static/uploaded/htmlarea/files/Decowe_Hall_Higson_and_Bullivant.pdf

[16] Harvey, L. and Knight, P.1996. Transforming higher education, open university press, Buckingham

[17] Hirshleifer, J.1980. Price Theory and applications, Englewood Cliffs, N.J.: Prentice-Hall. (p. 265)

[18] Sutherland, J. 2008. "Higher education, the graduate and the labour market: from Robbins to Dearing", Education + Training, Vol. 50 Iss: 1, pp.47 - 51

[19] Liu, Z. 1992. Ownership and Productive Efficiency: With Reference to British Ports. University of London: PhD thesis.

[20] Makulilo, V. B. 2012. "The proliferation of private Universities in Tanzania: quality compromised?" Wudpecker Journal of Educational Research Vol. 1(4) http://www.wudpeckerresearchjournals.org

[21] Materu, P. 2007. "Higher education quality assurance in Sub-Saharan Africa status, challenges, opportunities, and promising practices" THE WORLD BANK, Africa region human development department, Washington, D.C

[22] Msolla, P. 2000. Issues of higher education in Tanzania, ministry of higher education, science and technology

[23] Nkirila, S. 2009. The challenges of integrating entrepreneurship education in the vocational training system an insight from Tanzania's vocational education training authority, Journal of European Industrial, Emerald Group Publishing Limited

[24] Ordonez, R. M. 2012. "Exporting Filipino graduates to the global labor market: Its implications for Philippine higher education", Asian Education and Development Studies, Vol. 1 Iss: 1, pp.43 - 56

[25] Panagiotakopoulos, A. 2012. Employability skills development in Greek higher education institutions (HEls) Implications for policy makers, Higher education, skills and work-based learning Vol. 2 No. 2, 2012

[26] Sebil, C., Quainoo, K. A., and Sam, N.B .2013. Measuring the academic efficiency of the four campuses of the university for development studies using Data envelopment analysis, European Scientific Journal July 2013 edition vol.9, No.20 ISSN: $1857-7881$

[27] [27] Thomas, $\mathrm{H}$ and Xiaoying Li. 2009. Mapping globally branded business schools: a strategic positioning analysis, Management Decision Vol. 47 No. 9, 2009, Emerald group publishing limited

[28] Tóth, R. 2009. Data envelopment analysis and the efficiency of higher education, International Conference on Applied Economics - ICOAE 2009

[29] United republic of Tanzania. 2004. Secondary education development plan (SEDP) Ministry of education and vocational training (MoEVT)

[30] United Republic of Tanzania. 2010. Higher Education Development Plan (HEDP): Enhanced Relevance, Access and Quality in Higher Education, Ministry of Education and Vocational Training (MoEVT)

[31] United republic of Tanzania. 2009. National public private partnership (PPP) policy, Prime minister's Office, November, 2009

[32] Vincová, K. 2005. Using DEA models to measure efficiency, BIATEC, Volume XIII, 8/2005, Technical University Košice 


\section{APPENDICES}

Appendix A: Technical efficiency and Scale Efficiency Results (Public Universities)

\begin{tabular}{llllllllllllc}
\hline & & & \multicolumn{1}{c}{ DMU NAMES } \\
\hline YEAR & RTS $^{*}$ & ARU & DUCE & MU & MUCE & MUHAS & OUT & SUA & UDSM & MEAN & DMUs \\
\hline $\mathbf{2 0 0 8}$ & CRS & 1.000 & 0.685 & 1.000 & 1.000 & 1.000 & 1.000 & 1.000 & 1.000 & $\mathbf{0 . 9 6 1}$ & $\mathbf{8}$ \\
& VRS & 1.000 & 0.685 & 1.000 & 1.000 & 1.000 & 1.000 & 1.000 & 1.000 & $\mathbf{0 . 9 6 1}$ & \\
& SE & 1.000 & 1.000 & 1.000 & 1.000 & 1.000 & 1.000 & 1.000 & 1.000 & $\mathbf{1 . 0 0 0}$ & \\
\hline $\mathbf{2 0 0 9}$ & CRS & 1.000 & 0.833 & 1.000 & 1.000 & 1.000 & 1.000 & 0.709 & 1.000 & $\mathbf{0 . 9 4 3}$ & $\mathbf{8}$ \\
& VRS & 1.000 & 0.842 & 1.000 & 1.000 & 1.000 & 1.000 & 0.958 & 1.000 & $\mathbf{0 . 9 7 5}$ & \\
& SE & 1.000 & 0.989 & 1.000 & 1.000 & 1.000 & 1.000 & 0.740 & 1.000 & $\mathbf{0 . 9 6 6}$ & \\
\hline $\mathbf{2 0 1 0}$ & CRS & 1.000 & 0.546 & 1.000 & 1.000 & 1.000 & 1.000 & 1.000 & 1.000 & $\mathbf{0 . 9 4 3}$ & $\mathbf{8}$ \\
& VRS & 1.000 & 0.790 & 1.000 & 1.000 & 1.000 & 1.000 & 1.000 & 1.000 & $\mathbf{0 . 9 7 4}$ & \\
& SE & 1.000 & 0.691 & 1.000 & 1.000 & 1.000 & 1.000 & 1.000 & 1.000 & $\mathbf{0 . 9 6 1}$ & \\
\hline $\mathbf{2 0 1 1}$ & CRS & 1.000 & 0.792 & 1.000 & 0.935 & 1.000 & 0.858 & 0.873 & 1.000 & $\mathbf{0 . 9 3 2}$ & $\mathbf{8}$ \\
& VRS & 1.000 & 0.858 & 1.000 & 1.000 & 1.000 & 0.881 & 1.000 & 1.000 & $\mathbf{0 . 9 6 7}$ & \\
& SE & 1.000 & 0.923 & 1.000 & 0.935 & 1.000 & 0.974 & 0.873 & 1.000 & $\mathbf{0 . 9 6 3}$ & \\
\hline $\mathbf{2 0 1 2}$ & CRS & 1.000 & 0.957 & 1.000 & 1.000 & 1.000 & 0.964 & 0.621 & 1.000 & $\mathbf{0 . 9 4 3}$ & $\mathbf{8}$ \\
& VRS & 1.000 & 0.958 & 1.000 & 1.000 & 1.000 & 1.000 & 0.773 & 1.000 & $\mathbf{0 . 9 6 6}$ & \\
& SE & 1.000 & 0.999 & 1.000 & 1.000 & 1.000 & 0.964 & 0.803 & 1.000 & $\mathbf{0 . 9 7 1}$ & \\
\hline
\end{tabular}

RTS* is return to scale efficiency which can either be; CRS - constant return to scale; VRS - variable return to scale or SE - scale efficiency 


\section{Appendix B}

Technical efficiency and Scale Efficiency Results (Private Universities)

\begin{tabular}{lccccccccccc}
\hline YEAR & RTS & AKU & HKMU & IMTU & MWUCE & SJUT & TUDARCO & TUMA & UOA & MEAN & DMUs \\
\hline $\mathbf{2 0 0 8}$ & CRS & 1.000 & 1.000 & 1.000 & 0.432 & 0.293 & 1.000 & 0.627 & 0.363 & $\mathbf{0 . 7 1 4}$ & 8 \\
& VRS & 1.000 & 1.000 & 1.000 & 1.000 & 0.444 & 1.000 & 0.955 & 1.000 & $\mathbf{0 . 9 2 5}$ & \\
& SE & 1.000 & 1.000 & 1.000 & 0.432 & 0.660 & 1.000 & 0.657 & 0.363 & $\mathbf{0 . 7 6 4}$ & \\
\hline $\mathbf{2 0 0 9}$ & CRS & 1.000 & 1.000 & 0.663 & 0.326 & 0.693 & 1.000 & 1.000 & 1.000 & $\mathbf{0 . 8 3 5}$ & \\
& VRS & 1.000 & 1.000 & 0.673 & 1.000 & 0.717 & 1.000 & 1.000 & 1.000 & $\mathbf{0 . 9 2 4}$ & 8 \\
& SE & 1.000 & 1.000 & 0.985 & 0.326 & 0.967 & 1.000 & 1.000 & 1.000 & $\mathbf{0 . 9 1 0}$ & \\
\hline $\mathbf{2 0 1 0}$ & CRS & 0.840 & 1.000 & 0.778 & 0.874 & 0.543 & 1.000 & 1.000 & 0.838 & $\mathbf{0 . 8 5 9}$ & \\
& VRS & 1.000 & 1.000 & 1.000 & 1.000 & 0.573 & 1.000 & 1.000 & 1.000 & $\mathbf{0 . 9 4 7}$ & 8 \\
& SE & 0.840 & 1.000 & 0.778 & 0.874 & 0.948 & 1.000 & 1.000 & 0.838 & $\mathbf{0 . 9 1 0}$ & \\
\hline $\mathbf{2 0 1 1}$ & CRS & 1.000 & 1.000 & 0.797 & 1.000 & 0.550 & 1.000 & 1.000 & 0.183 & $\mathbf{0 . 8 1 6}$ & \\
& VRS & 1.000 & 1.000 & 0.990 & 1.000 & 0.690 & 1.000 & 1.000 & 0.818 & $\mathbf{0 . 9 3 7}$ & 8 \\
& SE & 1.000 & 1.000 & 0.805 & 1.000 & 0.797 & 1.000 & 1.000 & 0.224 & $\mathbf{0 . 8 5 3}$ & \\
\hline $\mathbf{2 0 1 2}$ & CRS & 1.000 & 1.000 & 0.775 & 1.000 & 1.000 & 1.000 & 1.000 & 0.495 & $\mathbf{0 . 9 0 9}$ & \\
& VRS & 1.000 & 1.000 & 0.814 & 1.000 & 1.000 & 1.000 & 1.000 & 0.646 & $\mathbf{0 . 9 3 3}$ & 8 \\
& SE & 1.000 & 1.000 & 0.952 & 1.000 & 1.000 & 1.000 & 1.000 & 0.766 & $\mathbf{0 . 9 6 5}$ &
\end{tabular}

Source: Research data 


\section{Appendix C}

Number of Technical efficiency and Scale efficiency DMUs - (2008 -2012)

\begin{tabular}{|c|c|c|c|c|c|}
\hline YEAR & RTS & $\begin{array}{l}\text { EFFICENT PUBLIC } \\
\text { UNIVERSITIES }\end{array}$ & $\%$ & $\begin{array}{l}\text { EFFICENT PRIVATE } \\
\text { UNIVERSITIES }\end{array}$ & $\%$ \\
\hline \multirow[t]{3}{*}{2008} & CRS & 7 & $87.5 \%$ & 4 & $50.0 \%$ \\
\hline & VRS & 7 & $87.5 \%$ & 6 & $75.0 \%$ \\
\hline & SE & 8 & $100.0 \%$ & 4 & $50.0 \%$ \\
\hline \multirow[t]{3}{*}{2009} & CRS & 6 & $75.0 \%$ & 5 & $62.5 \%$ \\
\hline & VRS & 6 & $75.0 \%$ & 6 & $75.0 \%$ \\
\hline & SE & 6 & $75.0 \%$ & 5 & $62.5 \%$ \\
\hline \multirow[t]{3}{*}{2010} & CRS & 7 & $87.5 \%$ & 3 & $37.5 \%$ \\
\hline & VRS & 7 & $87.5 \%$ & 7 & $87.5 \%$ \\
\hline & SE & 7 & $87.5 \%$ & 3 & $37.5 \%$ \\
\hline \multirow[t]{3}{*}{2011} & CRS & 4 & $50.0 \%$ & 5 & $62.5 \%$ \\
\hline & VRS & 6 & $75.0 \%$ & 5 & $62.5 \%$ \\
\hline & SE & 4 & $50.0 \%$ & 5 & $62.5 \%$ \\
\hline \multirow[t]{3}{*}{2012} & CRS & 5 & $62.5 \%$ & 6 & $75.0 \%$ \\
\hline & VRS & 6 & $75.0 \%$ & 6 & $75.0 \%$ \\
\hline & SE & 6 & $75.0 \%$ & 6 & $75.0 \%$ \\
\hline
\end{tabular}

Appendix D

Reviewed Public Universities in 2008 - 2012

\begin{tabular}{llll}
\hline \multicolumn{1}{c}{ University Name } & Acronym & Location \\
\hline 1. Ardhi University & ARU & Arusha \\
2. Dar es Salaam University College of Education & DUCE & Dar es Salaam \\
3. Mzumbe University & MU & Morogoro \\
4. Mkwawa University College of Education & MUCE & Iringa \\
5. Muhimbili University of Health and Allied Sciences & MUHAS & Dar es Salaam \\
6. The Open University of Tanzania & OUT & Dar es Salaam \\
7. Sokoine University of Agriculture & SUA & Morogoro \\
8. University of Dar es Salaam & UDSM & Dar es Salaam
\end{tabular}

Source: Adapted from TCU website (2014 
ISSN 2278-5612

\section{Appendix E}

Reviewed Private Universities (2008 - 2012)

\begin{tabular}{lll}
\hline \multicolumn{1}{c}{ University Name } & Acronym & Location \\
\hline 9. Agakhan University & AKU & Dar es Salaam \\
10. Hubert Kairuki Memorial University & HKMU & Dar es Salaam \\
11. International Medical \& Technology University & IMTU & Dar es Salaam \\
12. Mwenge University College of Education & MWUCE & Kilimanjaro \\
13. St. John University of Tanzania & SJUT & Dodoma \\
14. Tumaini University Dar es Salaam College & TUDARCO & Dar es Salaam \\
15. Tumaini University Makumira Arusha & TUMA & Arusha \\
16. University of Arusha & UoA & Arusha \\
\hline
\end{tabular}

Source: Adapted from TCU website (2014) 